\title{
TRADUÇÃO, RELAÇÃO E A QUESTÃO DO \\ OUTRO: CONSIDERAÇÕES ACERCA DE UM PROJETO de tRaduÇÃo dA Trilogia SUl- americana AmazOnAS, De Alfred DÖBlin Mauricio Mendonça Cardozo
}

(DÖBLIN, Alfred. "O romance histórico e nós". Tradução de Marion Brepohl de Magalhães. História: Questões \& Debates, $\mathrm{n}^{\circ}$ 44. Curitiba: Editora UFPR, 2006: 36.)

(TODOROV, Tzvetan. A conquista da América: a questão do outro. Tradução de Beatriz Perrone-Moisés. São Paulo: Martins Fontes, 2003: 3)
O terrível é não ir de encontro ao seu próprio querer e ainda por cima delinear isto como terrível e degenerado.

Alfred Döblin

Pode-se descobrir os outros em si mesmo, e perceber que não se é uma substância homogênea e radicalmente diferente de tudo o que não é si mesmo; eu é um outro.

Tzvetan Todorov*

Em "A marcha do povo das mulheres", primeira parte do primeiro livro de sua Trilogia Sul-americana, Döblin reconta a narrativa de origem das Amazonas - o povo das mulheres -, que, lideradas por Toeza, então uma das mulheres do cacique de sua tribo, insurge-se contra a condição geral de vida das mulheres, mata os homens da tribo e sai em guerra contra os povos que encontra ao longo de sua marcha. Os dois excertos abaixo dão mostra dos eventos que alavancam a reviravolta. Na voz de uma índia mais velha, à noite, em torno da fogueira, o primeiro excerto dá notícia da condição de vida das mulheres na tribo:

Uma jovem casou-se com um marido rico. Todos lhes desejaram felicidades, trouxeram-lhes presentes. Os pais fingiam chorar. Depois da festa, a moça e o marido cruzaram a lagoa. Lá chegando, o marido a mandou capinar e carpir a roça. Ao terminar, a mulher ainda tinha de fazer pirão, assar o pão. Não havia lenha. O marido mandou catá-la na mata. Era época das chuvas, o rio arrastara tudo, ela não achou muita lenha. $\mathrm{O}$ dia se foi, não catara o bastante. De volta em casa, o marido ralhou com ela. Na manhã seguinte, levantou-se e caminhou ainda mais longe mata adentro. Os bugios compadeceram-se dela, trouxeram-lhe lenha. Voltou para casa, o marido ficou insatisfeito, a mulher chegara tarde. Levantou-se ainda mais cedo no dia seguinte, os macacos jogavam-lhe os frutos maduros de cima do cacaueiro. Deliciou-se, catou lenha, os macacos a ajudaram. Voltou para casa, o marido ficou insatisfeito, a mulher 
ofegava, ele não gostou. E quando a lenha acabou de novo e ela teve de voltar outra vez à mata, chorou: - Pra que um marido rico se ele só me manda trabalhar? Se sou preguiçosa, sou bonita e me manda pra mata. Se trago lenha, sou feia, ele não me olha.

Contornando a lagoa, a jovem correu até sua mãe: - Por que vocês me casaram com um homem rico, se ele só me obriga a trabalhar? Preferia que vocês me tivessem dado em casamento a um bugio. Eles me dão cacau e me ajudam com a lenha. A mãe temeu que a filha pudesse juntar-se aos bugios.

Chamou então seu filho. Ele quebrou uma perna do sol. O sol pôsse a andar mais lentamente. $\mathrm{O}$ dia durou mais. A moça pôde então catar toda a lenha de que precisava, o marido ficou satisfeito."

O segundo excerto dá mostra da relação das mulheres com Valiarina, o jaguar negro que, ao ser assassinado pelos homens da tribo, acabaria por se tornar o estopim da revolta:

Onde entre as rochas se encontram as corredeiras, lá fica a gruta do jaguar negro, Valiarina é seu nome. Dizem que ele produz o ruído mouco das águas. É ali que as mulheres se banham. Toeza exclamou: - Os homens se foram. Por que é que eles partiram com arcos e flechas, escudo e zarabatana e com suas melhores canoas? Não disseram nada a ninguém. Esses nossos filhos mais jovens devem ser mais espertos que nós. O que estarão querendo? Foram buscar escravos e escravas que trabalhem para eles. Nas matas, espancam os homens até a morte e tomam suas mulheres, seus filhos. Eles vão ficar ricos e nós teremos de trabalhar ainda mais do que antes. Seria melhor partirmos logo pras lanças. Quando eles voltarem, iremos nos rebelar.

As mulheres brincavam na água, Toeza colheu um lírio e ergue-o em direção à cachoeira: - Ali mora o jaguar negro, meu noivo.

Enfeitou-se então com mais dez moças, armou-se, saiu novamente à caça.

Autor de romances históricos que tematizam contextos políticos e culturais tão distintos como a China do século XVIII, no romance Os três saltos de Wang-lun [Die drei Sprünge des Wanglun], de 1915, ou o Quirguistão do século XV, em sua reescritura do poema épico Manas, de 1927, ao perceber a irreversibilidade do rumo político que tomava seu próprio país, Alfred Döblin foi um dos primeiros escritores alemães de sua geração a deixar a Alemanha, em fevereiro de 1933, sendo também um dos primeiros a regressar ao país logo após o fim da Segunda Guerra Mundial. A opção política pelo exílio na França e nos Estados Unidos, que o distanciaria da Alemanha por 12 anos, seria um aspecto limitador de uma recepção mais ampla de sua obra e contribuiria decisiva-
*(DÖBLIN, Alfred. Das Land ohne Tod. Munique: DTV, 1991: 12, tradução minha)

" (lbidem: 13) 
·(DÖBLIN, Alfred. Berlin Alexanderplatz: Die Geschichte vom Franz Biberkopf. Munique: DTV, 2001) mente para que Döblin ficasse conhecido, no mundo da Literatura, quase que exclusivamente por seu romance Berlin Alexanderplatz, , publicado em 1929.

A maior parte de sua obra, em especial o que escrevera a partir da década de 30, teria uma repercussão bem mais pontual e discreta entre o público em geral. $\mathrm{E}$ isso se daria a despeito de sua obra ter sido contemplada com inúmeros estudos acadêmicos mundo afora, de ter sido traduzida, ainda que não tão amplamente, para algumas línguas como o tcheco, o polonês, o francês e o espanhol - praticamente toda sua obra é ainda inédita em português -, de ter movimentado algumas polêmicas com intelectuais como, por exemplo, Thomas Mann e de ter alcançado o respeito e admiração de escritores como Jorge Luis Borges e Günter Grass.

Uma de suas obras que se enquadra nesse rol de obras ainda bastante desconhecidas do público leitor em geral - embora relativamente bem estudada, em especial a partir do final da década de 70 - é o romance que Döblin publicaria em 1937 sob o título de Viagem à terra sem morte [Die Fahrt ins Land ohne Tod], obra que mais tarde integraria o primeiro dos três livros do que hoje se conhece como sua Trilogia Sul-americana intitulada Amazonas, de que fazem parte ainda o livro O tigre azul [Der blaue Tiger], de 1938, e A nova selva [Der neue Urwald], de 1947.

O primeiro livro desenvolve-se no contexto social e mítico dos povos indígenas que habitam a América do século XVI, em especial a região norte da Floresta Amazônica, e culmina com a chegada a essas terras dos conquistadores europeus, que dizimariam o Outro com que aí se deparam. O segundo livro desenvolve-se no contexto utópico das missões jesuíticas e tematiza os embates político-econômicos entre as monarquias portuguesa e espanhola e a igreja católica, que culminariam na destruição das reduções, na morte dos índios e na expulsão dos jesuítas. O terceiro livro salta alegoricamente para a Europa da primeira metade do século XX: a nova selva. No entanto, ainda que perspectivado por uma dimensão acontecimental do século XX, esse terceiro livro é fortemente marcado por uma diluição das temporalidades, em que tanto se dispõem analogicamente os conquistadores do século XVI, os "conquistadores” da Primeira Guerra Mundial e, com especial destaque, o "conquistador" nazista da Segunda Guerra Mundial, como também figuram os espíritos de Giordano Bruno, Galileu e Copérnico - em diálogo, num mesmo tribunal -, ou ainda, a figura 
mítica do Medievo polonês, espécie de Fausto de Cracóvia: o chamado Senhor Twardowski.

No abrangente estudo Wegweiser im Amazonas, ${ }^{1 *}$ George Sperber faz uma análise extensiva da gênese textual da Trilogia de Döblin, apontando suas diversas fontes e o modo com que o escritor as incorpora em seu romance. Esse estudo oferece subsídios suficientes para pensarmos a escritura döbliniana como sendo fortemente marcada pela apropriação, retextualização e ficcionalização das obras de etnólogos franceses e alemães que estudaram diversos povos indígenas em suas viagens pelas Américas. Entre nomes como Métraux, Charlevoix e Murr, figura também o nome de Theodor Koch-Grünberg, de cuja obra Mário de Andrade também se utilizara para escrever uma das obras canônicas da literatura brasileira, a rapsódia Macunaíma, o herói sem nenhum caráter, de 1928. Ainda que não tenham se servido exatamente do mesmo livro, como aponta Sperber," as obras de Mário de Andrade e Döblin encontram na obra desse etnólogo alemão um ponto de passagem em comum. Já desse ponto de vista, uma tradução brasileira da obra de Döblin representaria um desafio interessante, uma vez que consistiria: na produção de um texto em português, que tenha em vista articular uma relação tradutória com um texto em alemão, que, por sua vez, é produto de um esforço de apropriação, retextualização e ficcionalização de uma obra de cunho etnográfico, também escrita em alemão e que, na perspectiva de um etnólogo europeu do século XIX, teve por objeto um universo cultural e natural que não somente integraria o que hoje identificamos genericamente como universo cultural brasileiro (por mais que tal referencial esteja bastante distante de um contexto urbano contemporâneo), como também serviria de referência para a escritura de uma obra que integra o cânone de nossa literatura e sintetiza, na figura de seu protagonista "sem caráter", uma das expressões mais clássicas do ethos brasileiro.

Constituindo uma das fontes mais centrais em especial para o primeiro livro da Trilogia, a obra de Koch-Grünberg é de interesse não somente como ponto de aproximação, mas também pelo que ela oferece de diferente a Döblin e Mário de Andrade, que dela selecionam referências bastante distintas. Mário encontra o mito de Macunaíma na obra Do Roraima ao Orinoco, de 1924, en-

\footnotetext{
${ }^{1}$ Esse importante estudo renderia uma edição revista da Trilogia Amazonas na Alemanha, em 1988.
}

(SPERBER, George. Wegweiser im "Amazonas": Studien zur Rezeption, zu den Quellen und zur Textkritik der Südamerika-Trilogie Alfred Döblins. Munique: Tuduv, 1975)

(SPERBER, George. "Uma viagem à terra sem morte: a Trilogia Amazonas, de Alfred Döblin". Humboldt, no 63. Bonn: Goethe-Institut, 1992: 48-51.) 
(MAGALHÃES, Marion Brepohl de. "O ressentimento do exílio: a estética da perda em Alfred Döblin". In: BRESCIANI, Maria Stella; NAXARA, Marcia (org.). Memória e ressentimento: indagações sobre uma questão sensivel, 1 ed. Campinas: Unicamp, 2001: 491-506.)

(Ibidem: 502, grifos meus) quanto Döblin toma por base duas outras obras: Dois anos entre os indios do noroeste do Brasil, de 1909, e Lendas indígenas da América do Sul, de 1927. Para Sperber," essa diferença de recorte residiria no fato de que, enquanto Mário de Andrade buscava, como elemento de ficionalização, um herói "sem caráter", Döblin privilegiaria justamente uma visão mais próxima à do clássico bom selvagem rousseauniano.

No entanto, se por um lado esse bom selvagem é paradigma de um figura religada à physis, ao mundo natural, por outro lado, há nessa figura utópica um certo esvaziamento (justificável no contexto da discussão rousseauniana) da complexidade e da densidade do homem enquanto ser cultural, enquanto alguém a quem se impõem as complexidades da relação com seu próximo. Para Marion Brepohl de Magalhães, "a imagem do índio na obra do escritor alemão, em alguma medida, pode até mesmo estar muito próxima desse ideal clássico e utópico. Contudo: "No romance, o indígena não é o bom selvagem de Rousseau ou o canibal de tantos viajantes e cronistas europeus: é um povo dotado de cultura própria, autor da própria história, contra quem, em nome do racismo, os europeus arremessam sua violência."

Segundo Magalhães, portanto, na obra de Döblin, esse homem índio dizimado pelo homem branco não se resumiria nem à figura do primitivo imaculado, nem à figura do antropófago selvagem, extremos tipológicos que impossibilitam a construção de qualquer relação capaz de aceitar um Outro em sua própria alteridade. Ao contrário, Döblin constrói esse homem índio döbliniano como Homem, com a complexidade relacional de qualquer ser humano, como um Outro que tem cultura e história próprias, com grande destaque, aí, para o atributo "próprio".

É nisso que se funda mais centralmente o caráter de "crítica civilisatória radical" pelo qual sua obra é conhecida, ainda que seja importante, aqui, precisar melhor a dimensão dessa crítica. E é também nisso que reside a grande diferença dessa obra de Döblin: o modo como o autor equaciona a dimensão da alteridade enquanto uma questão. Pois ao construir esse Outro como um Outro a quem se concede o direito de "ser", a despeito das diferenças, de "ser diferente", de "ser à diferença" - em especial na percepção de um europeu - e adensar essa diferença com a complexidade das especificidades culturais que encontra nos registros etnográficos - resistindo à tendência comum de construir um Outro que não passe de um 
símile de si próprio, de um outro-Eu -, Döblin instaura, também para esse Outro, uma rede complexa de relaçōes culturais. E ao fazer isso, esse Outro passa a figurar não somente como um Outro qualquer, mas também como um Outro que se depara com barreiras e dificuldades ao tentar lidar com a complexidade da sua própria relação com os Outros: com seus Outros mais próximos, como na relação complexa entre homens e mulheres de uma mesma tribo; e com seus Outros mais distantes, como na relação com outros povos indígenas ou até mesmo com o homem branco. E nessas relações, assim como nas relações de alteridade do homem branco-europeu, há também malogro e incompreensão, violência e crueldade.

Nesse sentido, podemos entender que esse Outro ameríndio na obra de Döblin, mais do que simples contrapeso de articulação de uma crítica à civilização europeia, ${ }^{*}$ seria, antes, elemento central de articulação de uma crítica à própria condição humana de relação com o Outro. Pois ao flagrar nesse Outro, tão aparentemente distante, um Outro que habita uma complexidade relacional que é tão familiar a um homem europeu, e ao perceber nesse Outro, aparentemente tão diferente, um Outro que não apenas sofre, mas que, como ele próprio, também faz sofrer, Döblin articula, para além de sua crítica a um modo de relação do homem europeu, uma espécie de crítica à razão relacional, que coloca, antes, a própria condição em que se instauram as relações humanas como foco sóciocrítico de sua obra. E é nessa perspectiva que se pode afirmar que a obra de Döblin antecipa, em algumas décadas, um certo grau de problematização da questão da alteridade que só passaria a figurar, com comparável densidade, na obra de outros intelectuais (como Adorno, Hannah Arendt, Tzvetan Todorov, entre outros) ao longo da segunda metade do século XX.

A questão, no âmbito destas considerações preliminares, é pensar numa possibilidade de rearticulação de uma equação relacional tão complexa - como a que equaciona a questão döbliniana da alteridade - no caso de uma tradução brasileira de Amazonas.

É importante destacar a ideia de que Döblin não equaciona uma relação meramente transitiva, dicotômica e hierárquica entre uma cultura dita civilizada e outra dita primitiva. Ainda que a narrativa alemã se desenvolva em uma terra distante, às margens do mundo civilizado europeu, com personagens míticas de uma mitologia completamente estranha a um cidadão europeu comum da primeira metade do século XX - portanto, em uma atmosfera cul-
* (Cf. STAUFFACHER, Werner. "Nachwort des Herausgebers" [Posfácio do organizador da edição]. In: DÖBLIN, Alfred. Alfred Döblin: Amazonas Romantrilogie. org. Werner Stauffacher. Munique: DTV, 1991: 242.)

(Cf. HEINZE, Dagmar. Kulturkonzepte in Alfred Döblins Amazonas-Trilogie: Interkulturalität im Spannungsverhältnis von Universalismus und Relativismus. Trier: WVT Wissenschaftlicher Verlag Trier, 2003.) 
tural alheia à lógica do logos e da razão ocidental, já que fundada e estruturada sob o signo do mito, do rito, do simbólico -, a obra não explora esse "outro mundo" apenas como um mundo exótico. Ao contrário, o escritor constrói um "mundo outro" em que, a despeito de sua alteridade radical, o homem índio habita uma condição tão insuspeitavelmente complexa quanto à do próprio homem branco europeu. Nesse sentido, a obra de Döblin convida o leitor a descobrir não apenas um Outro radicalmente diferente e exótico, mas também a descobrir-se nesse Outro aparentemente tão distinto e, nisso, confrontar-se com sua, antes insuspeitável, proximidade humana. Em outras palavras, ao convidar o leitor para um exercício de "tradução do Outro", Döblin surpreende esse leitor por oferecer-lhe uma possibilidade de "traduzir-se nesse $\mathrm{Ou}$ tro", produzindo o efeito de leitura que dá sustentação a seu exercício de crítica civilizatória. Quanto ao estatuto dessa crítica, talvez possamos afirmar que, de fato, Döblin parece tematizar mais centralmente os afãs eurocêntricos. No entanto, a dimensão de sua crítica não se reduz apenas a isso, na medida em que se entendem tais afãs não como ponto focal, mas sim, como eixo em torno do qual Döblin promove um movimento crítico que põe em questão a própria condição humana de relação com o Outro, como já mencionado anteriormente.

Para Döblin e para um leitor alemão, esse Outro da relação é um Outro que, por ser percebido inicialmente como distante e diferente, cumpre o fim de instaurar uma tensão diferencial que coloca o leitor em uma condição de suspensão que se projeta para um ponto de distensão, para um momento da leitura, epifânico e surpreendente, em que o leitor flagra, nesse Outro, um semelhante, um próximo.

Ao traduzir o romance para o português, esse primeiro elemento de alteridade radical seria amenizado quanto a sua natureza diferencial, pois, ainda que distante histórica, geográfica e culturalmente, esse homem índio, em alguma medida, faz parte do imaginário de um leitor brasileiro comum, até mesmo para um brasileiro urbano, do sul do país, para quem esse referencial cultural amazônico, ao mesmo tempo que é bastante distante, também se apresenta como algo, de certo modo, familiar.

Numa tradução brasileira, portanto, a equação döbliniana sofreria um redimensionamento crítico, na medida em que o movimento de traduzir-se no Outro se daria em função de uma relação 
que não parte, inicialmente, da experiência de uma alteridade radical, mas sim, da relação com um Outro que se apresenta como uma dimensão de alteridade de sua própria identidade. Ou seja: da relação com um Outro que se apresenta com um eu mais distante.

Numa tradução brasileira, a possibilidade de um momento epifânico da leitura se daria, então, não a partir da percepção de uma identidade com um Outro radicalmente diferente, mas sim, a partir da percepção de uma heterogeneidade na constituição de si mesmo. Para o leitor alemão, a surpresa da identidade na diferença colocaria em xeque sua presunção de alteridade radical. Para um leitor brasileiro, a surpresa da diferença na identidade poderia colocar em xeque sua presunção de identidade homogênea.

Um projeto de tradução brasileira da Trilogia de Döblin não poderia perder de vista, portanto, esse redimensionamento crítico da equação relacional, que, por sua vez, implicaria inúmeras consequências práticas para o processo de tradução da obra.

Um exemplo muito pontual de implicação prática desse redimensionamento diz respeito ao tratamento da grafia dos topônimos e dos nomes dos povos indígenas citados na obra. Em qualquer projeto de tradução de uma obra como Amazonas, seria certamente importante definir, já de partida, um padrão ortográfico para a reescritura do campo lexical de línguas indígenas. No caso da definição de um padrão que se orientasse pela discussão crítica apresentada aqui, palavras de origem indígena que começam com "y" - grafia típica dos textos etnológicos em língua espanhola, provavelmente por influência do Guarani, bem como nos textos de Koch-Grünberg - poderiam ser grafadas com “j”, visto que tal grafia é mais frequentes tanto na toponímia brasileira quanto em nossa literatura: yapura seria traduzido então por japurá. Ainda que este seja apenas um detalhe mínimo, uma decisão extremamente pontual, optar por um padrão ortográfico que não produza, num primeiro contato, um efeito de distanciamento justamente pela via do exótico, parece ser a estratégia mais produtiva para o redimensionamento da equação döbliniana numa tradução brasileira e para a consequente eficácia do efeito de flagrar uma dimensão de alteridade no corpo de uma identidade percebida aparentemente como monolítica.

Mas para que o texto traduzido não pareça meramente exótico aos olhos de um leitor brasileiro, não basta apenas estabelecer um padrão ortográfico. Em várias passagens, sobretudo quan- 
do se refere aos povos indígenas e à toponímia, Döblin opta sistematicamente pela paráfrase alemã do termo estrangeiro, em vez de simplesmente citar o nome na língua indígena de origem - que é como o termo é registrado, por exemplo, na obra de Koch-Grünberg, em que a paráfrase surge como estratégia de tradução do léxico indígena. Ao proceder desse modo, o escritor consegue fazer com que o leitor alemão vá se aproximando aos poucos do universo ficcional da obra, minimizando, assim, uma certa estranheza inicial que pudesse afastar demais um leitor para quem os termos em tupi e guarani fossem completamente opacos - o que poderia criar uma tensão diferencial demasiadamente grande, a ponto de impossibilitar uma eventual distensão e o efeito posterior de identificação do leitor com esse Outro da relação.

Levando isso em conta, podemos articular criticamente uma solução possível para um problema bastante recorrente na tradução para o português de Amazonas, a exemplo do que ocorre com os termos Krötenloch (Buraco do Sapo) e Entenleute (Povo dos Patos). A opção de tradução sistemática da forma parafrástica alemã, usada por Döblin, por uma forma parafrástica em português poderia criar, na tradução brasileira, um tom que nos remetesse menos a um universo indígena que nos é familiar, do que a um universo toponímico e antroponímico de que temos conhecimento apenas a partir de sua forma mais exótica e estereotipada, que ecoa o contexto dos filmes americanos de conquista do Velho Oeste, em que, por exemplo, o antropônimo Thathanka Iyothanka, em um dialeto da língua sioux, se transforma em algo como "Touro Sentado".

Assim, numa tradução brasileira, o topônimo Krötenloch poderia ser traduzido por Cururuquara, que além de ser o mesmo termo de que Döblin parte para fazer a paráfrase alemã e de existir de fato enquanto localidade, não soa tão exótico aos ouvidos de um leitor brasileiro acostumado a outros topônimos como Araraquara, Piraquara, etc. Já no caso de Entenleute, que designa um povo indígena específico, a simples tradução "literal" da paráfrase döbliniana para a língua tupi não oferece um resultado muito produtivo. No entanto, Döblin menciona que este povo habitava as margens do Rio Uaupés. Em consulta a um mapa da distribuição dos povos indígenas e do tronco linguístico Tupi-Guarani no Brasil, verifica-se que o povo predominante na região mencionada era o povo Tucano, justamente um dos povos estudados por Koch-Grünberg, o que poderia, por essa via, justificar a tradução Dicionário Tupi-Português: com esboço de gramática do Tupi Antigo. Santos: Traço Editora, 1984, contracapa.) de Entenleute por povo tucano. 
Uma outra questão bastante relevante para a tradução brasileira da Trilogia de Döblin diz respeito ao estilo da escritura döbliniana. Em Amazonas, o escritor constrói seu universo ficcional como um anatomista. A narrativa se desenvolve a partir da economia e da precisão de movimentos sintáticos curtos e calculados, e do uso incessante de uma pausa sintática que mantém presente, pois em evidência, uma dimensão de silêncio na textura narrativa döbliniana - elementos estilísticos tão impactantes numa prosa de língua alemã acostumada a períodos imensos e encadeamentos lógicos de alta complexidade. É como se Döblin não permitisse que o leitor se limitasse a navegar a superfície de um contínuo narrativo e inebriante de leitura, em que seria maior o risco de esse $\mathrm{Ou}$ tro passar despercebido pelo leitor. É como se Döblin induzisse o leitor ao mergulho e, nisso, é como se o forçasse a ir dissecando aos poucos esse corpo alheio e opaco. É como se o escritor instaurasse, a cada hesitação ante às subordinações sintáticas, um ritmo próprio, que, de tão quebrado e elementar, adquire um poder incisivo, contundente. É justamente esse movimento cirúrgico que contribui, no plano formal, para a eficácia do exercício de "traduzir-se no Outro", realizado como uma operação em que, ao lançar o olhar forçosamente atento em direção a um Outro, o leitor acaba flagrando a si próprio.

Nesses termos, uma tradução brasileira não poderia simplesmente optar pela pasteurização da sintaxe do texto em prol de uma leitura mais fluente. Ainda que o potencial de impacto de tal estratégia discursiva seja bem menor em português do que em alemão, é preciso, também em língua portuguesa, reencenar esse movimento cirúrgico no plano formal, colocando em evidência os períodos curtos, o movimento constante de esquiva às subordinações e, assim, pensando uma possibilidade crítica de tradução que, em vez de reduzir-se à dimensão do dito, leve em conta a dimensão do silêncio na tradução dessa narrativa.

A Trilogia de Döblin, se entendida nos termos aqui discutidos, como obra que tematiza ficcionalmente a condição humana da relação com o Outro, coloca o tradutor diante de uma tarefa que não se reduz ao equacionamento das relaçōes linguísticas, culturais e estéticas mais evidentes de todo trabalho de tradução literária. Caberá ao tradutor preocupado com as questōes levantadas pelo viés de leitura aqui proposto redimensionar também a própria ordem crítica que movimenta a obra döbliniana e pesar as suas consequências 
em cada momento de decisão ao longo de todo processo de tradução. Somente um prática tradutória ciente de sua natureza crítica será capaz de oferecer ao público leitor brasileiro uma experiência de leitura digna da densidade e da complexidade com que Döblin conseguiu articular a questão da alteridade: uma experiência que abre a possibilidade de nos flagrarmos no Outro, mesmo que esse gesto nos mova contra nossos próprios quereres. Com Döblin, pode-se pensar que esse movimento é muito menos uma ameaça, do que um gesto de chance e risco que nos move adiante.

\section{Mauricio Mendonça Cardozo}

Doutor em Letras - Alemão pela USP e professor do Curso de Graduação e do Programa de Pós-graduação em Letras da UFPR, em Curitiba. Como pesquisador, atua na área dos Estudos da Tradução, desenvolvendo trabalhos nos campos da Tradução Literária, da Crítica e da Teoria da Tradução. Como tradutor, publicou, entre outros, A Assombrosa História do Homem do Cavalo Branco (2006) e $O$ Centauro Bronco (2006), um projeto de dupla tradução da novela Der Schimmelreiter, do escritor alemão Theodor Storm.

\section{Resumo}

Palavras-chave: tradução; relação; questão do Outro; alteridade; Döblin.
Em 1937, Alfred Döblin publicava Viagem à terra sem morte, romance que mais tarde constituiria o primeiro volume do que hoje se conhece como sua Trilogia Sul-americana Amazonas. Valendo-se da obra de etnólogos como Theodor Koch-Grünberg, de cuja obra Mário de Andrade também se utilizara para criar seu Macunaíma, Döblin não faz simplesmente uma tradução exoticizante dos registros etnográficos de uma cultura "primitiva" a partir da perspectiva de uma cultura "civilizada". Ao contrário, o autor convida o leitor a descobrir-se nessa cultura pretensamente primitiva. Em outras palavras, em vez de simplesmente proporcionar uma experiência de "tradução do Outro", Döblin convida o leitor a "traduzir-se nesse Outro", flagrando-o em sua antes insuspeitável proximidade humana. Propõe-se aqui a discussão da equação Döbliniana da "relação com o Outro" em Amazonas, como fundamentação crítica de um projeto de tradução dessa obra para o português do Brasil. 
Abstract

The Journey to the Land without Death (1937) is the first of the three volumes of Döblin's South-America Trilogy Amazonas. Based upon the work of ethnologists like Theodor KochGrünberg, whose work constitutes also an important reference for Mario de Andrade's Macunaima (1928), Döblin doesn't simply translate those ethnographic notes of a "primitive" culture on the perspective of a culture that pretends to be "civilized": he invites the reader to discover himself in this other culture apparently so "primitive". In other words, instead of simply experiencing a "translation of the other", Döblin invites the reader to "translate himself upon this Otherness", finding out an Other that is unbelievably human. This paper aims at a preliminary discussion of Döblin's Alterity equation, i.e. of the way he poses the problem of Otherness in his Trilogy. This discussion outlines the critical principles of a possible translation project of this work to Brazilian Portuguese.

\section{Résumé}

En 1937, Alfred Döblin publiait Voyage à la terre sans mort, roman qui constituerait plus tard le premier volume de ce qui est connu de nos jours comme sa Trilogie Sud-américaine Amazonas. S'inspirant de l'oeuvre d'ethnologues comme Theodor Koch-Grünberg, oeuvre dont Mário de Andrade s'est également servi pour créer son Macunaima, Döblin ne fait pas qu'une simple traduction aux couleurs exotiques des registres ethnographiques d'une culture primitive à partir de la perspective d'une culture civilisée. Au contraire, il invite son lecteur à se découvrir dans cette culture soi-disant primitive. Autrement dit, au lieu de proposer une simple expérience de traduction de l'Autre, Döblin invite le lecteur à "se traduire dans cet Autre”, le dévisageant dans son insoupçonnable proximité humaine. Il s'agit ici de la discussion de l'équation döblinienne de la question de la relation à l'Autre dans Amazonas, comme fondement critique d'un projet de traduction de cette oeuvre en brésilien.
Key words: translation; relation; Otherness; alterity; Döblin.

Mots-clés: traduction; relation; question de I'Autre; altérité; Döblin. 